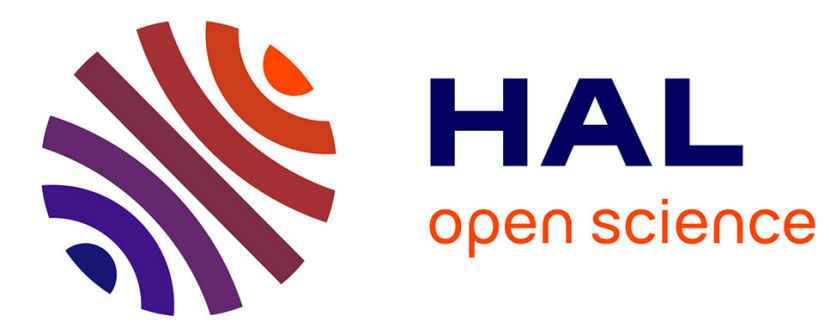

\title{
In-situ measurements of wave impact pressure on a composite breakwater: preliminary results
}

Benoît Larroque, Philippe Arnould, Franck Luthon, Pierre-Antoine Poncet, A Rahali, Stéphane Abadie

\section{- To cite this version:}

Benoît Larroque, Philippe Arnould, Franck Luthon, Pierre-Antoine Poncet, A Rahali, et al.. In-situ measurements of wave impact pressure on a composite breakwater: preliminary results. Journal of Coastal Research, 2018, 85, pp.1 - 5. 10.2112/SI85-001.1 . hal-01809649

\section{HAL Id: hal-01809649 \\ https://hal.science/hal-01809649}

Submitted on 10 Jul 2018

HAL is a multi-disciplinary open access archive for the deposit and dissemination of scientific research documents, whether they are published or not. The documents may come from teaching and research institutions in France or abroad, or from public or private research centers.
L'archive ouverte pluridisciplinaire HAL, est destinée au dépôt et à la diffusion de documents scientifiques de niveau recherche, publiés ou non, émanant des établissements d'enseignement et de recherche français ou étrangers, des laboratoires publics ou privés. 


\title{
In-situ measurements of wave impact pressure on a composite breakwater: preliminary results
}

\author{
B. Larroque $\uparrow$, P. Arnould $\ddagger$, F. Luthon $\ddagger$, P.A. Poncet $\uparrow$, A. Rahali $\uparrow$ and S. Abadie $* \dagger$ \\ $\dagger$ SIAME $\quad \ddagger$ LIUPPA Computer Science Lab \\ MIRA FR 4155, Univ. Pau \& Pays Adour, FRANCE. MIRA FR 4155, Univ. Pau \& Pays Adour, FRANCE.
}

\begin{abstract}
A detached horizontally composite breakwater protecting the Saint Jean de Luz bay (French Basque Coast, Bay of Biscay, France) has been equipped with two pressure sensors displayed vertically onto the vertical wall. The two sensors recorded wave impact pressure in ten minute burst each hour at $10 \mathrm{kHz}$. In parallel, incoming waves were also recorded about $1 \mathrm{~km}$ off the structure with a directional wave buoy giving access to spectral wave parameters as well as raw data. Finally water level, wind magnitude and direction were also acquired. The whole dataset covers winter 2015-2016 from January to March.

The results show first the statistical distribution of the measured parameters confirming preceding similar studies in which significantly lower impact pressure values were obtained compared to physical experiments or numerical simulations. A linear multivariate model has then been adjusted showing the overwhelming influence of wave heights to explain maximum pressure variability, followed by water level. Nevertheless this result has still to be confirmed for data reduced to impulsive impacts. Finally, interesting events supposedly corresponding to, or approaching flip-through impact type, have been identified and need further investigations.
\end{abstract}

ADDITIONAL INDEX WORDS: coastal structure, supervision, embedded sensor, environmental variables, field data, flip-through impact, statistical analysis.

\section{INTRODUCTION}

This article addresses the short time scale impulsive impact which may be generated by a breaking or quasi-breaking wave when meeting a vertical structure. This problem has been studied extensively in the past due to its important contribution to the structure loading. Basically, the impact can be seen as the superposition of several mechanisms. The main part of the impact is driven by the local free surface shape. It is well known in the slamming or sloshing communities that very high pressures can be generated by near head-on liquid impacts (Wagner, 1932). This kind of impact generates a very fast uprising jet (obviously faster and faster with deadrise angles approaching zero) associated to large pressure gradient. This is the reason why the most violent impacts are generated by the so-called "flip-through" impact (Cooker and Peregrine, 1990 ; Cooker and Peregrine, 1992) in which wave through and wave crest focus toward the same point where huge pressures are generated. Anyway, the problem is not only a matter of free surface shape. Breaking waves can also trap some air volume when interacting with a vertical wall. This gas pocket will interact with the free surface during impact, modulating the purely free surface impact. This problem was first addressed by Bagnold (1939) in his piston-like model. Normally, the air effect is to cushion the impact and redistribute the pressure hence diminishing the pressure peak, but air can also be entrained as air bubbles. The effect of this may be to increase the overall water compressibility leading to complex effects able to increase the pressure peaks. Lots of experimental studies have been conducted to explore this complex process (see Bullock et al. (2007), Hofland, Kaminski, and Wolters (2011) or Kaminski and Bogaert (2009) among others) leading to important findings.

While experimental works are valuable and necessary to refine the understanding of the phenomenon, they suffer from significant departures from the natural process occurring on coastal structures at sea. First, most experimental studies are conducted in $2 \mathrm{D}$ while the natural process is essentially $3 \mathrm{D}$. This could lead to over or underestimation of the maximum pressure (Peregrine, 2003). Secondly, experiments and prototypes are different in scale and they are also different regarding the fluid involved. The scale is usually much larger in the prototype (although recent large scale experiments approach the real scale (Hofland, Kaminski, and Wolters, 2011)). So, scaling is necessary to extrapolate at the prototype scale. But as the fluids involved in experiments and prototypes are different, seawater being difficult to employ in lab experiments, the appropriate scaling rule is difficult to find (Bullock et al., 2001). Thirdly, real breakwaters often exhibit a protective block armor unit which decreases the wave destructive power and therefore may diminish impact pressure. Last, environmental variables such as wind magnitude and direction, water level, and wave directions are generally not taken into account in laboratory studies. For all these reasons, there is a need for field measurements of wave impact pressure.

De Rouville, Besson, and Petry (1938) made the first attempt to measure wave impact in the field. These measurements were made at the Dieppe breakwater using the first pressure sensors available (quartz piezoelectric sensors of $6 \mathrm{~cm}$ diameter with a natural frequency higher than $1 \mathrm{kHz}$ ). In this study, the largest pressures recorded ranged from 1.8 to 6.9 bar, the latter being the largest value ever recorded on site. More recently, Bird et al. (1998) developed a specific sensor to record wave impacts on vertical walls measuring pressure as well as air content. They conducted field measurements at the Alderney breakwater and showed inversely proportional variation of pressure and aeration and impact pressure values up to 3.96 bar (Bullock et al., 2001).

The current paper presents preliminary results of a four months field measurement of wave impact pressures at two points of the Artha breakwater. First, the experimental set-up is presented, 
followed by preliminary statistical and wave by wave signal analysis.

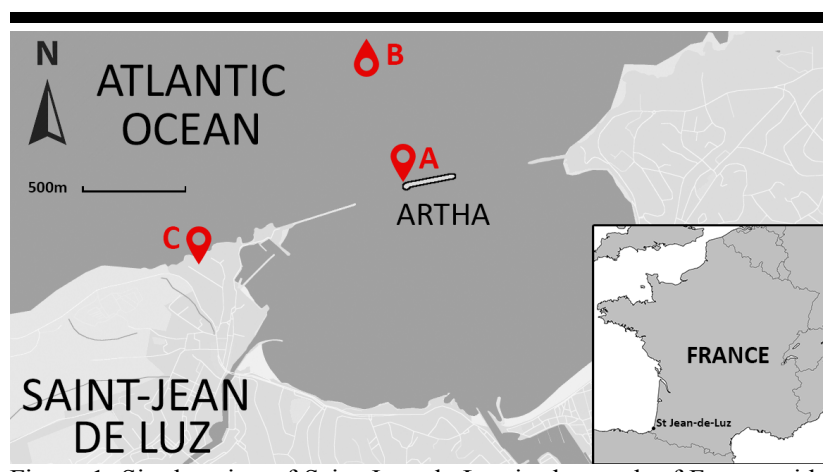

Figure 1. Site location of Saint Jean de Luz in the south of France with sensors location (A. Breakwater with pressure sensors, B. Wave buoy, C. Weather station).

\section{METHODS}

The structure considered in this work is the Artha breakwater located in Saint Jean de Luz (French Basque Coast, Bay of Biscay, France) (Figure 1). This breakwater was built in 1890 to protect the bay of Saint Jean de Luz from flooding and agitation, and in particular the port of Saint Jean de Luz - Ciboure which is a famous marina and fishing harbor active since the 15 th century. The depth in front of the structure is large enough (i.e., between 15 and $10 \mathrm{~m}$ deep) to allow the largest waves to break in the vicinity of the structure or directly on it. The breakwater is a horizontally composite breakwater including a large central wall made up of a mix of concrete and stones, surrounded by a concrete berm. Both elements are lying on a large mound composed of 50 tons parallelepiped concrete blocks.

The experimental set-up was deployed in November 2015. First, two pressure sensors were integrated in the offshore-facing wall at the location where the largest wave energy was expected to strike the wall. This position was determined thanks to visual observation of recurrent damages combined with wave statistics analysis. It is located at the left end of the structure (west round head) on a recurved part of the wall (Figure 2). Piezo-resistive sensors PAA25 (Keller@) with a natural frequency of $1 \mathrm{kHz}$ and IP68 protection rating were selected to record wave impact pressure. The sensors were embedded vertically on the structure, one sensor in the lower part of the wall (measurement range 0-5 bar) and the other in the upper part (measurement range $0-10$ bar). These measurement ranges were chosen after preliminary tests conducted in 2014-2015 involving 0-50 bar sensors, showing a significant lack of accuracy due to the somehow low impact pressures recorded. The present measurements are still considered as preliminary tests, explaining the choice of two different measuring ranges. The sensors exhibit a linear transfer function between the 4-20 mA electrical current output $I$ and the measured pressure $P$ reading: $P=P_{M}(I-K) /\left(K_{l}-K\right)$ where $P_{M}$ is the pressure sensor range, $\mathrm{K}=4.10^{-3}$ and $\mathrm{K}_{1}=20.10^{-3}$. Keller sensors are calibrated and tested to guaranty a linearity error of 0.07 times the full scale, which for the present sensors, leads to an error of 0.0035 bar for the $0-5$ bar lower sensor, and 0.007 bar for the $0-10$ bar upper sensor.

The data acquisition and transmission system consists of three main parts: (i) power supply (isolated site), (ii) acquisition system and (iii) data transmission (Figure 3 ).

The Artha breakwater is a detached structure, therefore it was necessary to design an installation to provide electrical power to the measurement devices and the data communication system. For that purpose, a photovoltaic power supply was implemented (Figure 3) whose components are: a solar charge controller (Steca Solarix $($ PRS 1010 12/24V 10A), a photovoltaic panel SolarWorld $\subset 150 \mathrm{Wc}$ and a high capacity battery Banner(C SBV $200-12$ V 200Ah.

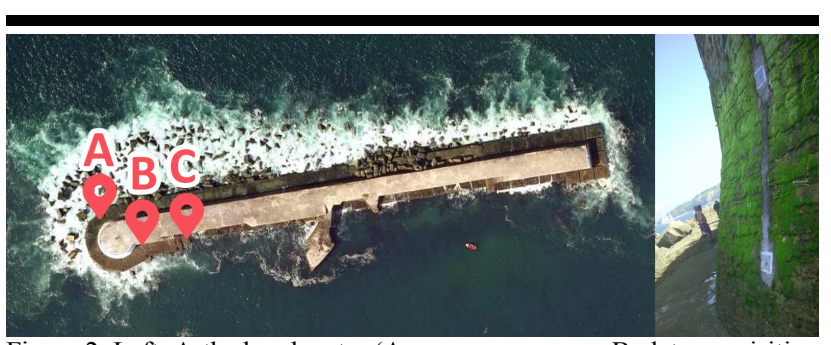

Figure 2. Left: Artha breakwater (A. pressure sensors, B. data acquisition system, C. photovoltaic panel and data transmitter unit). Right: photograph of the 2 pressure sensors embedded in the wall structure.

Due to the isolated site of the Artha breakwater, it was necessary to choose a flexible data acquisition system which could be remotely programmable. To that end, a CompactRIO 9076 from National Instruments $(\mathcal{C}$ was deployed, whose advantages are: embedded control, rugged package, modular acquisition modules, linux embedded system (a webserver might be useful for remote communication), high storage memory, FPGA base board (high sampling rate $<1 \mathrm{MHz}$ ). This acquisition system can control 4 modules (NI-9203 $\pm 20 \mathrm{~mA}$, 8-Channel, 16 bits) where 8 sensors can be plugged on each module (for instance a total capacity of 32 pressure sensors of Keller $($ PAA2 25 type). The quantization error due to digital acquisition is equal to 0.0002 bar for the upper sensor and 0.0001 bar for the lower sensor.

A wireless system is used to communicate with the data acquisition system. This system, based on a $3 \mathrm{G}$ router (3G UR5i v2, 3G UMTS/HSPA) and a virtual private network (VPN), allows to communicate with the data acquisition system to program, change experimental parameters, and get measurement results from any authorized computer of the university.

*Corresponding author: stephane.abadie@univ-pau.fr 


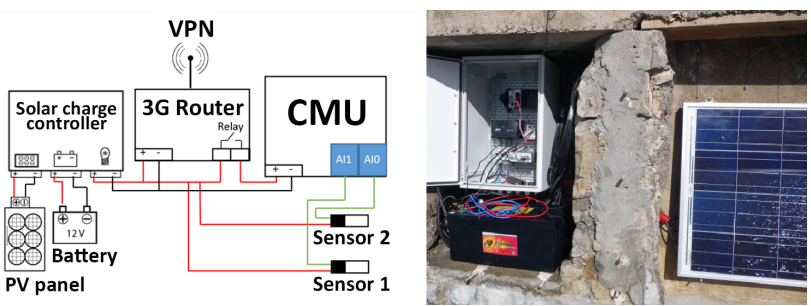

Figure 3. Installation setup on the breakwater. Left: Block-diagram. Right: Photograph.

A software application was developed allowing to interact with all the programs or data handled by the data acquisition system with several remote functionalities. With this application, it is possible to change the embedded program, the experimental parameters or retrieve the data stored. Standard web data communication protocols (i.e., http, ftp) are used to fulfil these functionalities: (i) webservices (http) to control experiments (experiment in progress, time remaining, start/stop of an experiment) or to get information on the storage, (ii) ftp transfers to download experimental results. For instance, during strong storms, it was sometime not possible to download the entire file (typical measurement file size is $27 \mathrm{Mo}$ ) all at once, because wave overtopping was reaching the antenna and switched off the $3 \mathrm{G}$ signal. To solve this issue, an additional storage was added allowing to wait until the end of the storm period to retrieve the current data measurements. To help data transfer, it was necessary to transform raw data (in Ampere), which required double precision data bytes (64 bits) in lighter integer values ( 16 bits) by converting them into micro-Ampere. Hence, the data stored by the data acquisition system actually varies from $4000 \mu \mathrm{A}$ to $20000 \mu \mathrm{A}$.

By default, the system automatically records measurements from the sensors at the beginning of each hour during 10 minutes $\left(\mathrm{T}_{\mathrm{acq}}\right)$ and with a sampling frequency $\left(\mathrm{f}_{\mathrm{s}}\right)$ of $10 \mathrm{kHz}$. The latter is meant to oversample the pressure signal compared to the natural frequency of the pressure sensors $(1 \mathrm{kHz})$ to later be able to perform efficient postprocessing.

Waves were also measured thanks to a wave buoy, part of the Candhis network (Centre d'archivage national de données de houle in-situ, candhis.cetmef.developpement-durable.gouv.fr/), located about $1000 \mathrm{~m}$ west off the Artha breakwater (Figure 2) in $20 \mathrm{~m}$ water depth. This buoy provides the raw signal (i.e., instantaneous free surface elevation) as well as usual wave statistical and spectral parameters. Additionally, wind velocity and direction (at $10 \mathrm{~m}$ ) were taken from the Meteo France station at Socoa semaphore. To best fit the pressure data, wind data were extracted as the maximal $10 \mathrm{~min}$, every hour. Finally, water level was given by a mathematical model (Arnoux et al., 2018) based on a harmonic analysis of the data collected locally at the Socoa tidal station and a correction term to account for atmospheric pressure effect.

Data was continuously collected from November 2015 to April 2016 except for a few short time periods where either the wave buoy or the pressure data acquisition system were not properly working. The amount of data collected, very large, needs postprocessing to be efficiently analyzed (Rahali, 2017). First, a Gaussian filter was applied on the raw data to get rid of high frequency noise induced by transmission. Then, a low-pass filter with a cut-off frequency of $1 \mathrm{kHz}$ was applied to remove all the information that the sensor cannot capture due to its natural frequency limitation.

The data is composed of a large amount of ten minute files containing wave by wave pressure signals. On each file, first, a detection of actual impacts is performed considering the following rules (Rahali, 2017) on the relative pressure: $\mathrm{P}>0.1$ bar, duration $>1 \mathrm{~s}$, time interval between impacts $>3 \mathrm{~s}$, at least 5 impacts in $10 \mathrm{~min}$. Then a statistical computation is carried out in order to compute the following statistical parameters: PMAX, $_{\text {MA }}$ associated time tmaX, $\mathrm{P}_{1 / 10}$, PMEAN, impact numbers n, ПMAX, $\Pi_{1 / 10}$ (with $\Pi$ being the pressure impulse).

\section{RESULTS}

Environmental parameters are analyzed in this section. Wave parameters are calculated based on $30 \mathrm{~min}$ of continuous data acquisition at the wave buoy position. During the field campaign, significant wave height was mainly between $1 \mathrm{~m}$ and $1 \mathrm{~m} 50$, with the most frequent maximal wave height around $2 \mathrm{~m}$. The maximal significant wave height which occurred during this period is 7.57 $\mathrm{m}$ and the maximal wave height, $12.98 \mathrm{~m}$. The most frequent significant period is around $12 \mathrm{~s}$ and the maximal significant period $18 \mathrm{~s}$. As regards wave direction, it mainly ranges between $300^{\circ}$ to $320^{\circ}$. These values are typical of a classical winter season not particularly energetic in the bay of Biscay. At the Socoa semaphore, the most frequent wind speed is between 2 and $4 \mathrm{~m} / \mathrm{s}$ and the maximal wind speed is $25.9 \mathrm{~m} / \mathrm{s}(93 \mathrm{~km} / \mathrm{h})$. The most frequent wind orientations are between $250^{\circ}$ and $300^{\circ}$ (WestNorth-West) corresponding to typical onshore winds. But the distribution presents a very localized peak around $180^{\circ}-200^{\circ}$ that could be explained by local effects. Finally, water levels range from $0.1 \mathrm{~m}$ to $4.9 \mathrm{~m}$ (Marine Charts convention) and the distribution exhibits two peaks at about $1.6-1.8 \mathrm{~m}$ and 3.4-3.6 m corresponding respectively to frequent low and high tide water levels.

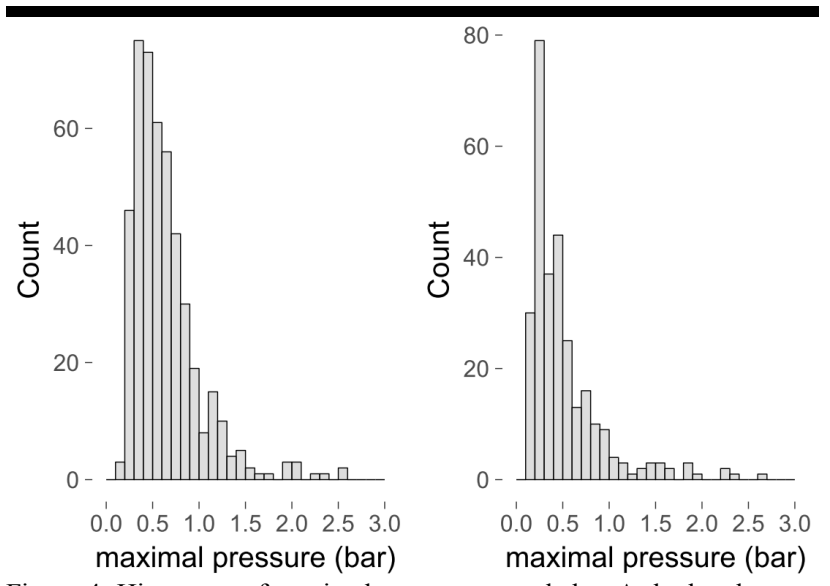

Figure 4. Histogram of maximal pressure recorded at Artha breakwater. Left: bottom sensor, Right: top sensor.

The histograms in Figure 4 show the repartition of $\mathrm{P}_{\mathrm{MAX}}$ (minus atmospheric pressure) from both top and bottom sensors. First of all, logically, there are more measurements at the bottom sensor as its lower elevation makes it more easily reachable by waves. It 
can also be noted that the most frequent maximal pressure on the bottom sensor is slightly higher than at the top sensor yet still below 0.5 bar. Strong impacts ( $\mathrm{P}_{\mathrm{MAX}}>1.5$ bar) appear approximately at the same frequency at both sensors but they are distributed differently. Hence, for instance, the maximal pressure recorded by the bottom sensor ( 2.59 bar) is slightly lower than at the top sensor (2.70 bar).

One aim of this work is to determine the combined environmental conditions (waves, wind, water level) creating the favorable conditions for the largest impact pressure to occur. For that purpose a multivariate linear model was calculated with the "lm" routine from R software, to model the variation of maximal pressure according to significant wave height and period, swell direction, water level and wind speed and direction. All the variables were scaled before applying the algorithm in order to be able to compare the respective correlation coefficients. Overall, these variables explain $58 \%$ of the variability of the data. An ANOVA test to this multivariate model showed, as expected, that the most important variable is wave height explaining $45 \%$ of the whole variability. Water level explains $8.5 \%$, swell direction $3.7 \%$ and wave period less than $0.5 \%$ of the whole variability. Wind influence (velocity and direction) appears not significant in this model.

Within each 10 min event, it is possible to study each impact individually and try to identify specific signal shape patterns. The quantity of data is large and hence the results presented here are only very preliminary. Two types of pressure signal were identified during this preliminary work, intense impacts (up to 3.5 bar - absolute value) with a very short rise time followed by a sharp decrease of pressure to moderate values $(\sim 1.3$ bar) (Figure 5) and impacts also reaching high pressure values (around 2.5 bar) but with longer rise time and followed by a regular pressure decay (Figure 6). Each impact type is well captured by the sensor and even the shorter rise time is correctly resolved with several records.

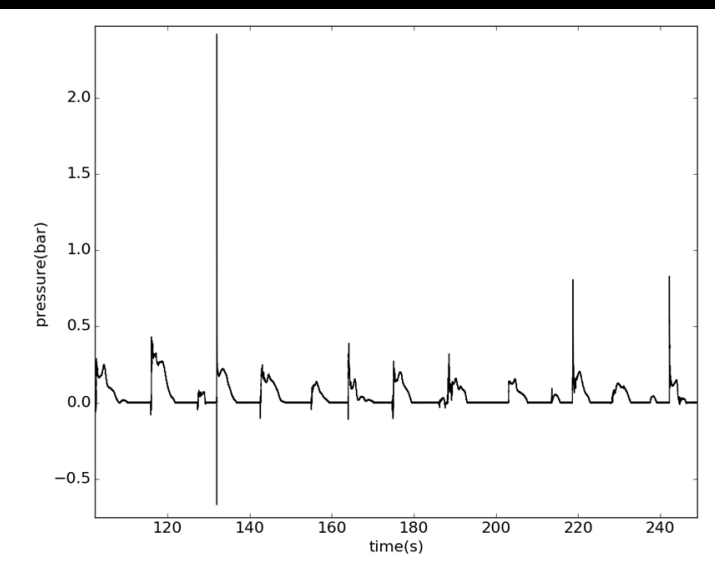

Figure 5. Illustration of short and intense impacts.

The impact presented in Figure 5 corresponds to one of the strongest impacts recorded at the top sensor over the measurement period. It occurred simultaneously with the highest water level for which an impact was recorded during that period. During this event, waves were relatively small with $\mathrm{H}_{1 / 3}$ about 2.2 $\mathrm{m}, \mathrm{Th}_{1 / 3}$ of $10 \mathrm{~s}$ and a North-West swell direction $\left(317^{\circ}\right)$. The wind was light $(6.5 \mathrm{~km} / \mathrm{h})$ and coming from the south $\left(180^{\circ}\right)$. Whereas the impacts plotted on Figure 6 happened for more energetical conditions corresponding to a classical winter storm with $\mathrm{H}_{1 / 3}$ of $5.5 \mathrm{~m}, \mathrm{Th}_{1 / 3}$ of $13.8 \mathrm{~s}$ and a North-West swell direction $\left(327^{\circ}\right)$. The wind was moderate $(30 \mathrm{~km} / \mathrm{h})$ and coming from the west $\left(260^{\circ}\right)$. It is obvious that the impacts of Figure 6 generate higher pressure impulse values compared to the impacts of Figure 5 and consequently larger resulting forces even though this parameter cannot be calculated due to the limited number of sensors used here.

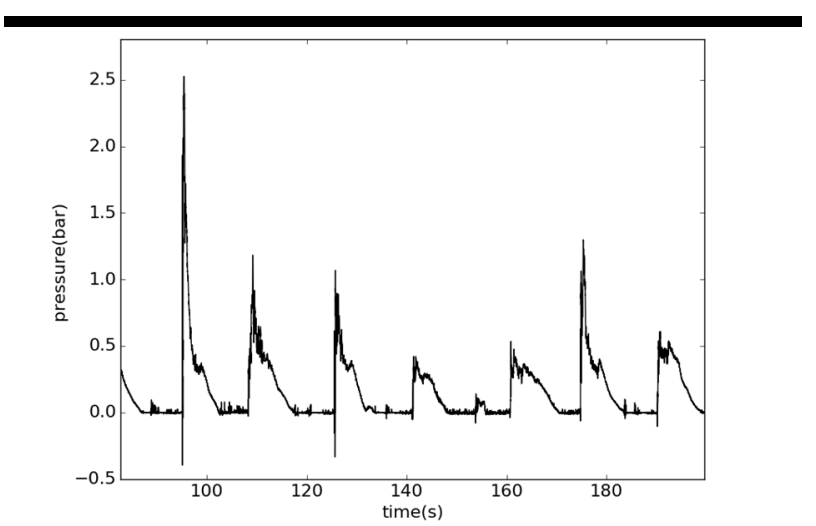

Figure 6. Illustration of slower impacts.

\section{DISCUSSION}

In this paper, new field measurements of wave impact pressure on a vertical caisson submitted to energetic wave climate have been presented. Maximal pressure values recorded during the present field experiment are at least an order of magnitude smaller than pressure recorded in waves flumes and still smaller than the values observed at Alderney and Dieppe breakwaters. This can be surprising as wave climate in Saint Jean de Luz is notably more energetic than in Dieppe for instance. Two reasons may explain this result. First, the Artha breakwater is protected by massive 50 ton blocks disseminated all around the breakwater. This block armor unit forces most of the waves to break significantly before the caisson wall and dissipate their energy within the blocks. This was not the case in Alderney or Dieppe. Secondly the Artha breakwater is orientated almost North (slightly West) while most waves come from the west-northwest direction. To capture these incoming energetic waves, sensors were placed on the left part of the breakwater on a curved portion of the wall. Because of this, the generated pressure may be reduced compared to a planar wall face as in Alderney or Dieppe breakwaters.

A linear multivariate model was developed to relate impact pressure to incoming waves, water level, and wind. This model explains $58 \%$ of the variability of the data, and significant wave height by itself explains $45 \%$. This result is logical as this analysis was performed on the whole dataset and considering the $\mathrm{P}_{\mathrm{MAX}}$ parameter, therefore including the whole range of pressure values and mostly moderate impacts. It is likely that this dataset is mainly composed of non-impulsive impacts (i.e., involving no or very modest peaks) which are known to mainly depend on wave height. This model was also used under the approximation of independent events and variables. Refining data and model could 
allow to better explain the influence of secondary variables. It may be more interesting to perform the same analysis but only on impulsive impacts and therefore considering individual waves. This will require to identify the corresponding environmental parameters and especially the corresponding incoming wave which requires additional work.

An obvious limitation of this study is the use of only two sensors. It is well known (e.g., Bullock et al., 2001) that strong pressure peaks appear only very locally. Therefore it is likely that larger pressure values may be obtained by a more refined sensor network. Additionally, a sensor network covering the vertical as well as the horizontal direction may help determining the dynamics of the pressure pulse which is of importance in order to define the type of impact occurring. It was shown in Figure 5 the occurrence of very short intense impact pressure associated to moderate wave height. This type of event is of course not well predicted by the linear multivariate model and, as a matter of fact, the residual value is the largest of all the dataset for this event. This event is nevertheless very interesting as it implies a large pressure increase followed by a sharp decrease. As such it appears very similar to the one presented in Bredmose et al. (2010), obtained in a physical experiment subsequently to a flip-through impact. This assertion is supported in our data by the fact that the pressure pulse travelled very quickly in this particular event $(0.05$ s) whereas, in most of the other events, this travelling time was significantly longer.

\section{CONCLUSIONS}

Preliminary results of a new field measurement of wave impact pressures on a composite breakwater located in Saint Jean de Luz French Basque coast (Bay of Biscay) were presented in this paper. The following results have been obtained:

- the experimental set-up was found to be adapted to the extreme conditions met in this location and continuous good quality measurements were obtained for the first four months test period.

- maximum pressures measured are significantly lower than in precedent published physical or numerical experiments. This confirms precedent findings.

- a linear multivariate model was developed to relate maximum pressures to environmental parameters showing the predominant role of wave height followed by water level. This work has to be pursued for impulsive impacts.

- $\quad$ interesting events, which may be close to a flip-through process, were identified and need more investigations.

To allow more comprehensive analysis, an actual 2D network of 16 pressure sensors covering horizontal and vertical directions will be installed in winter 2017-2018.

\section{ACKNOWLEDGMENTS}

The authors would like to thank Prof. Benoit Liquet for fruitful discussions on the statistical aspect of this work. The authors acknowledge financial support from the European POCTEFA program MAREA EFA046/15, the "extreme events" AST OASU program, OCA, and the University of Pau \& Pays Adour through the API program. Financial support from ISITE program E2S for the $\mathrm{PhD}$ fellowship of Pierre Antoine Poncet is gratefully acknowledged. Finally, the authors would like to thank the staff from CD64 department in charge of the breakwater maintenance, and especially its former manager Alain Roudil, for their help in preparing and installing the experimental set-up.

\section{LITERATURE CITED}

Arnoux, F., Abadie, S., Bertin, X., and Kojadinovik, I., 2018. A database to study storm impact statistics along the Basque Coast. Proceedings from the International Coastal Symposium (ICS) 2018 (Busan, South Korea), Journal of Coastal Research, Special Issue N ${ }^{\circ} 85$.

Bagnold, R.A., 1939. Interim report on wave-pressure research. Technical report, Institution of Civil Engineers.

Bird, P.A.D., Crawford, A.R., Hewson, P.J., and Bullock, G.N., 1998. An instrument for field measurement of wave impact pressures and seawater aeration. Coastal Engineering, 35(1998):103-122.

Bredmose, H., Hunt-Raby, A., Jayaratne, R., and Bullock, G. N., 2010. The ideal flip-through impact: experimental and numerical investigation, Journal of Engineering Mathematics, 67(1), 115-136.

Bullock, G.N., Crawford, A.R., Hewson, P.J., Walkden, M.J.A., and Bird, P.A.D, 2001. The influence of air and scale on wave impact pressures. Coastal Engineering, 42(4):291312.

Bullock, G.N., Obhrai, C., Peregrine, D.H., and Bredmose, H., 2007. Violent breaking wave impacts. part 1: Results from large-scale regular wave tests on vertical and sloping walls. Coastal Engineering, 54(8):602-617.

Cooker, M.J. and Peregrine, D.H., 1992. Wave impact pressure and its effect upon bodies lying on the sea bed. Coastal Engineering, 18(3):205-229.

Cooker, M.J. and Peregrine, D.H., 1990. A model for breaking wave impact pressures. Coastal Engineering Proceedings, 1(22):1473-1486.

De Rouville, A., Besson, P., and Petry, P., 1938. Etat actuel des études internationales sur les efforts dus aux lames. Annales des Ponts et Chaussées.

Hofland, B., Kaminski, M., and Wolters, G., 2011. Large scale wave impacts on a vertical wall. Coastal Engineering Proceedings, 1(32):15.

Kaminski, M.L. and Bogaert, H., 2009. Full scale sloshing impact tests. In The 19th International Offshore and Polar Engineering Conference (Osaka, Japan), International Society of Offshore and Polar Engineers.

Peregrine, D.H., 2003. Water-wave impact on walls. Annual Review of Fluid Mechanics, 35(1):23-43.

Rahali, A., 2017. Analyse des données issues des enregistrements des impacts réels des vagues sur la digue d'Artha. Anglet, France : Univ. Pau \& Pays Adour, Master's thesis, 63p.

Wagner, H., 1932. The phenomena of impact and planing on water. NACA translation, 1366. 